\title{
Láser en dermatología
}

\author{
Laser in dermatology
}

\section{María Isabel Arredondoㅁ, Luz Adriana Vásquez ${ }^{1}$, Juan Esteban Arroyave ${ }^{1}$, Verónica Molina ${ }^{1}$, Delsy Yurledy Del Río ${ }^{1}$, Julieth Herrera²}

1. Médicos dermatólogos, Hospital Pablo Tobón Uribe, Medellín, Colombia.

2. Médico, residente de Dermatología de cuarto año, Instituto Dermatológico de Guadalajara, Jalisco, México.

\section{Resumen}

El láser es el acrónimo de Light Amplification by Stimulated Emission of Radiation (amplificación de luz por emisión estimulada de radiación); ha sido usado por décadas en la dermatología y cada vez tiene más aplicaciones en la especialidad. Se presenta un artículo enfocado en el tema, con conceptos básicos basados en publicaciones médicas y en experiencias propias.

PALABRAS CLAVE: dermatología, láser, terapia láser, tatuajes, telangiectasias.

\section{Summary}

Laser (Light Amplification by Stimulated Emission of Radiation) has been used for decades in dermatology and its applications in this medical specialty are ever increasing. We present an article which focuses on this topic, encompassing basic concepts based on published literature and on our own experiences.

KEY WORDS: Dermatology, laser therapy/instrumentation, laser therapy/ methods, lasers, tattooing, telangiectasis/therapy.
Correspondencia:

María Isabel Arredondo

Email:

mariaiarredondo@gmail.com

Recibido: 28 de enero de 2014 . Aceptado: 18 de marzo de 2014.

No se reportan conflictos de interés.

\section{Historia}

Láser es el acrónimo de Light Amplification by Stimulated Emission of Radiation (amplificación de luz por emisión estimulada de radiación). El primer láser fue desarrollado en 1959 por Maiman, quien usó un cristal de rubí para producir una luz roja de $694 \mathrm{~nm}$; después aparecieron el neodimio:itrio en 1961, el aluminio granate Nd:YAG en 1962, el argón en 1963 y, en 1964, el dióxido de carbono $\left(\mathrm{CO}_{2}\right)$. Fueron Goldman, et al., los que establecieron su papel en dermatología con el uso del láser rubí para tatuajes y desde 1983 sus usos se han ampliado enormemente, especialmente luego de que Anderson y Parrish postularan la teoría de la termólisis selectiva con la consiguiente destrucción selectiva de un cromóforo ${ }^{1}$.

\section{Fundamentos del láser}

Un láser es un dispositivo que es capaz de generar un haz de luz colimada (unidireccional, donde cada rayo de luz se considera paralelo a los demás), monocromática (con una sola longitud de onda de un solo color), y coherente (todas las ondas están acopladas en longitud, amplitud y número, estando todas en una misma fase de tiempo y espacio).

Puede ser de emisión espontánea cuando consta de una fuente energética externa, óptica, mecánica, química o eléctrica encargada de excitar los electrones del medio productor que, al absorber la energía, pasan a una órbita distante del núcleo del átomo y, una vez vuelven a su órbita original, liberan la energía absorbida en forma de otro fotón. La emisión de radiación estimulada ocurre cuando un átomo estimulado es es- 
CAVIDAD ÓPTICA

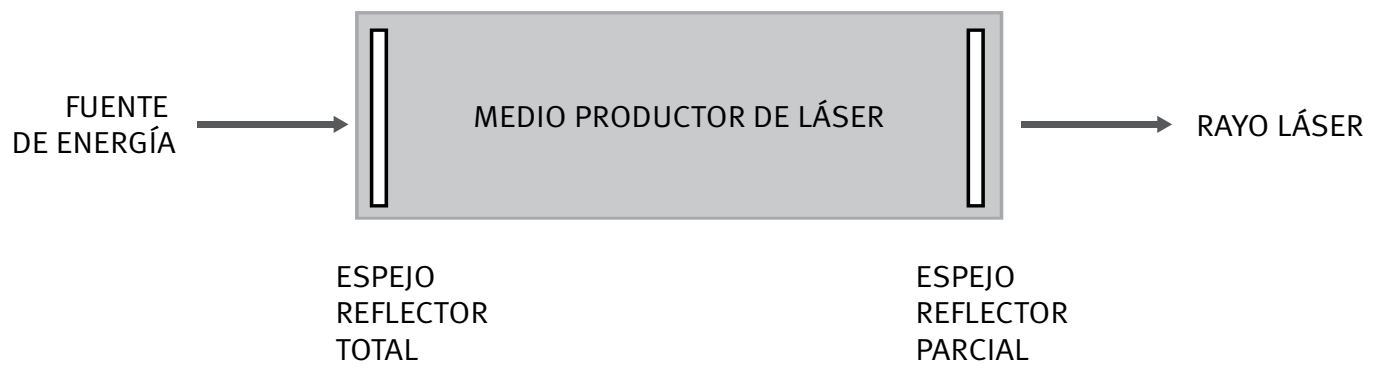

FIGURA 1. Representación esquemática del funcionamiento del láser.

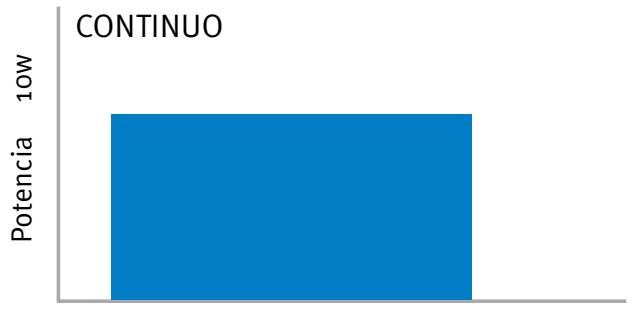

Tiempo (segundos)

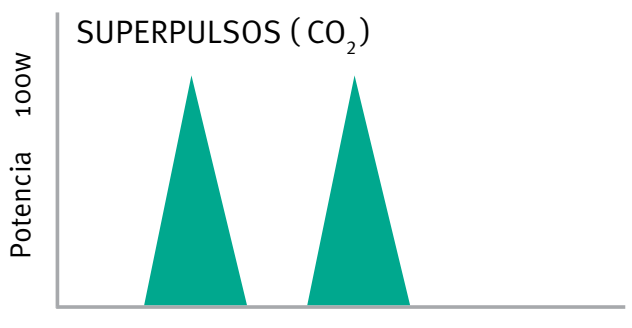

Tiempo (Centésima de microsegundos)

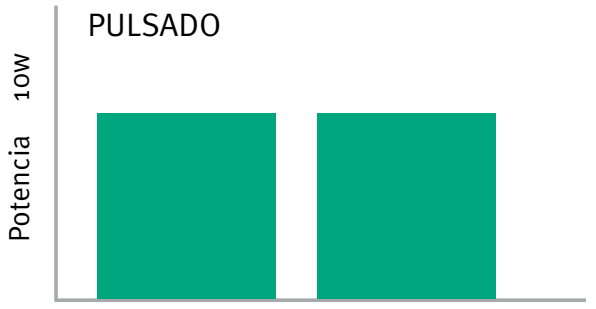

Tiempo (Milisegundos)

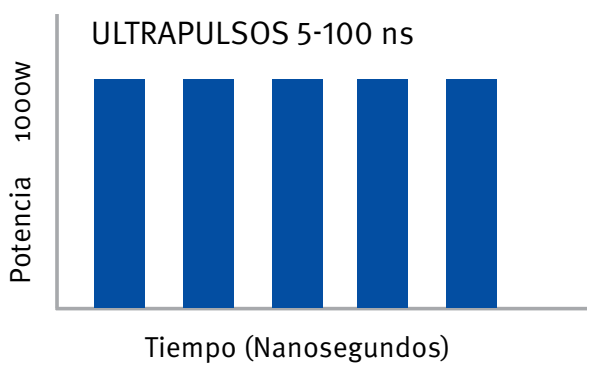

FiguRA 2. Tipos de emisión de láser.

timulado por otro fotón de energía antes de volver a su órbita normal, emitiendo dos fotones que viajan en la misma dirección y con la misma frecuencia, es decir, con un recorrido igual en espacio y tiempo. Esto ocurre continuamente en la cámara de un láser, la cual tiene en su interior un medio productor de láser que puede ser sólido (rubí o cobre), líquido (colorantes o dye laser), de semiconductores (arseniato de galio) o gaseosos (dióxido de carbono), siendo estos medios los que determinan la longitud de la onda de la radiación producida.

Además, la cámara en su interior tiene dos espejos reflectores, uno total y otro parcial, que reflejan los átomos excitados que emiten fotones; estos fotones, a su vez, excitan átomos y así se aumenta la producción de fotones. De estos, aproximadamente, el $15 \%$ escapa por la reflexión parcial y forma el rayo láser. Finalmente, hay un mecanismo conductor del rayo que es articulado o de fibra óptica (FIGURA 1) 2 .

La luz emitida puede ser: continua, con una onda constante de bajo poder, que produce destrucción no selectiva de tejido (láser $\mathrm{CO}_{2}$ y argón); casi continua, con emisión de energía de manera interrumpida $\left(\mathrm{KTiOPO}_{4}\right)$ (fosfato potásico de titanio), vapor de cobre, kriptón y APTD (Argon Pumped Aunable Dye); pulsada, que emite energía en pulsos ultracortos con intervalos de 0,1 a $1 \mathrm{~s}$, con picos de poder mayores a los emitidos en la forma continua y que, a su vez, se dividen en pulso amplio de $450 \mu \mathrm{s}$ a $40 \mathrm{~ms}$, ultrapulsados de 5 a $100 \mathrm{~ns}$ o superpulsados $\left(\mathrm{CO}_{2}\right.$ que es modificado para producir pulsos muy cortos de forma repetida) (FIGURA 2). 


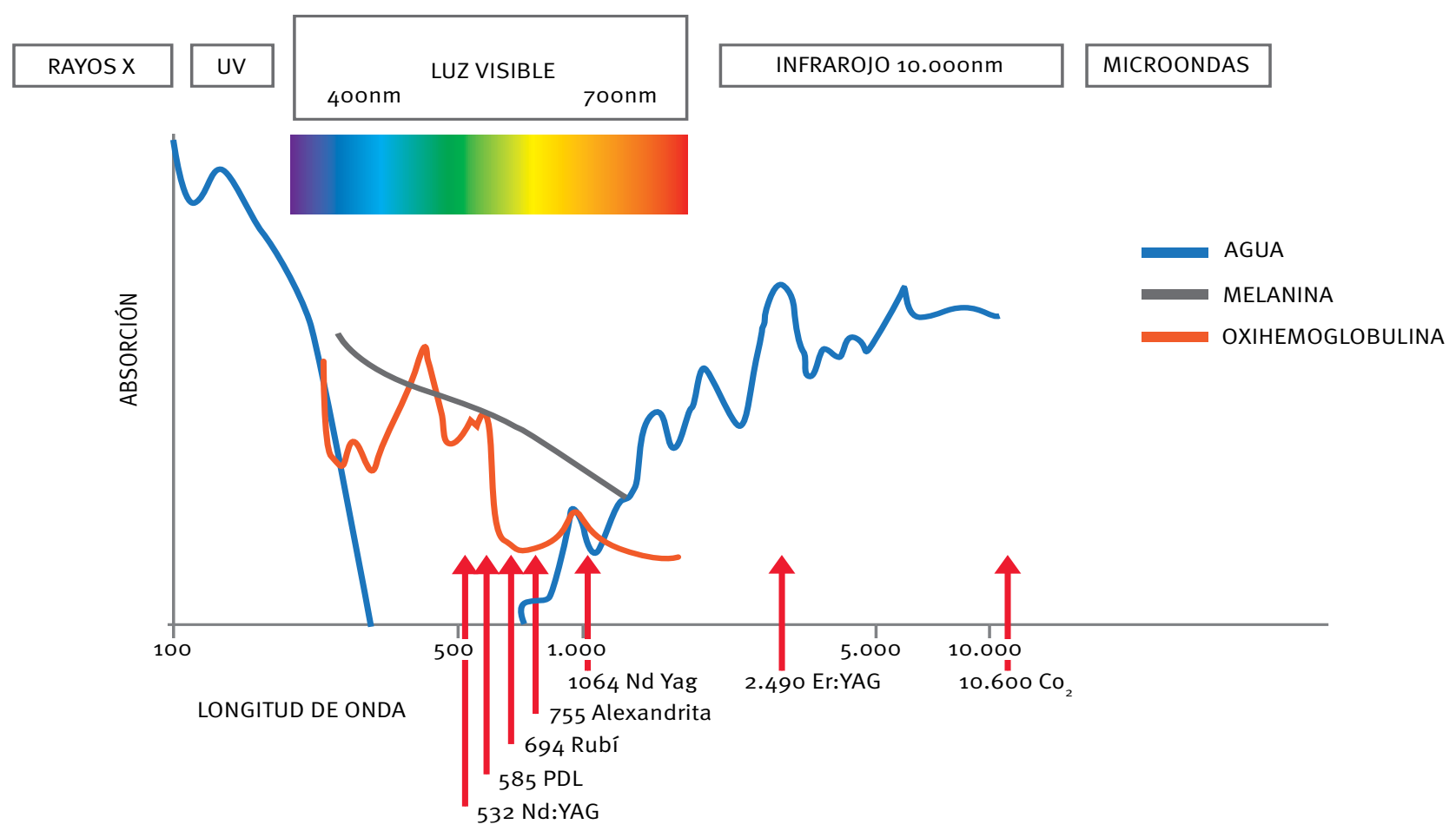

FigurA 3. Puntos de absorción de los cromóforos en la piel.

\section{Óptica cutánea}

Según la ley de Fresnel, 4 a 7 \% de la luz emitida por el láser se refleja al entrar en contacto con la piel, por la diferencia en el índice de refracción entre el aire $(n=0)$ y la capa córnea $(n=1,45)$. El 93 al $96 \%$ restante penetra la piel, donde se dispersa, difundiéndose lateralmente sin daño tisular; se transmite, profundizándose más allá de la zona de absorción, y se absorbe por el fotón, que cede su energía a un átomo denominado 'cromóforo', el cual está representado en la piel por la hemoglobina, la melanina y el agua, cada uno con bandas características de absorción a determinadas longitudes de onda.

Con respecto al espectro de luz UVA, UVB, luz visible y cercana a las regiones infrarrojas, las mayores longitudes de onda penetran a un nivel más profundo en las estructuras de la piel, ya que el rayo de luz se dispersa menos en la dermis. Los espectros de luz lejanos del infrarrojo y de la luz visible penetran menos profundamente en la dermis, porque el agua y las proteínas de la epidermis absorben en mayor medida la luz del rayo de energía (FIGURA 3).

$\mathrm{Al}$ aplicar el láser en dermatología se produce calor, con la consiguiente desnaturalización de algunas de las estructuras vitales; es un proceso gradual producido por la combinación de tiempo y temperatura. Se sabe que cerca de una temperatura crítica se produce una coagulación rápida $\mathrm{y}$, al mismo tiempo, la energía producida por los tejidos se convierte en calor y por conducción se difunde a los tejidos circulantes.

Para que un cromóforo específico sea destruido preservando los tejidos que se encuentran alrededor, se requiere que la duración de pulso del rayo de energía sea más corta o igual que el tiempo de relajación térmica de dicha estructura. El tiempo de relajación térmica es el requerido para que el tejido pierda la mitad del calor que adquirió con el impulso del láser; se sabe que este equivale en segundos, aproximadamente, al cuadrado de la dimensión del objeto en milímetros. Esta destrucción selectiva de un cromóforo determinado es favorecida, además, por la selección de la longitud de onda ideal para ser absorbida por la molécula elegida, la duración del impulso y el flujo ideal ${ }^{3}$ (TABLA 1).

\section{Evaluación previa}

Todos los pacientes requieren una consulta antes del inicio del tratamiento, para una evaluación médica completa en la que se clasifica el fototipo de piel según Fitzpatrick. Se deben evaluar las expectativas del paciente, tomar fotos antes del inicio del tratamiento; explicar los posibles riesgos: cicatriz, formación de 


\begin{tabular}{|c|c|c|}
\hline Término & Definición & Unidad \\
\hline Energía & Unidad fundamental de trabajo & $\mathrm{J}$ \\
\hline Potencia & Intensidad a la que se administra la energía & W \\
\hline Fluencia & $\begin{array}{l}\text { Cantidad de energía administrada por unidad } \\
\text { de área }\end{array}$ & $\mathrm{J} / \mathrm{cm}^{2}$ \\
\hline Irradiancia & $\begin{array}{l}\text { Potencia administrada expresada en Watts/ } \\
\text { por unidad de área, } \mathrm{cm}^{2}\end{array}$ & $\mathrm{~W} / \mathrm{cm}^{2}$ \\
\hline Duración del pulso & Duración de exposición al láser & Segundos o milisegundos \\
\hline Cromóforo & Medio que absorbe la luz & Hemoglobina, melanina o agua \\
\hline $\begin{array}{l}\text { Tamaño de la pieza de mano } \\
\text { (SPOT) }\end{array}$ & $\begin{array}{l}\text { Diámetro del haz de láser en la superficie } \\
\text { cutánea }\end{array}$ & $\mathrm{mm}$ \\
\hline
\end{tabular}

Tabla 1. Términos de láser usados en dermatología.

ampollas, úlceras, foliculitis, acné, hiperpigmentación o hipopigmentación, recurrencia o pobre respuesta al tratamiento y se debe obtener la firma del consentimiento informado ${ }^{4}$.

Contraindicaciones relativas: antecedentes de queloides o de cicatrices hipertróficas.

Contraindicaciones absolutas: ingestión de medicamentos fotosensibilizadores, toma de isotretinoína en los últimos seis meses, lupus eritematoso, antecedentes de enfermedades con fenómeno de Koebner, embarazo (a pesar de que hasta ahora no hay evidencia de lesiones al feto).

Los pacientes con historia de herpes cerca del sitio del procedimiento, deben recibir profilaxis 24 horas antes y siete días después.

No se debe tener exposiciones solares las cuatro semanas previas, ni durante el tiempo que dure el tratamiento, y se debe recomendar el uso diario de protector solar ${ }^{5}$.

\section{Enfriamiento de la piel para proteger estructuras vecinas}

A pesar de seleccionar adecuadamente la longitud de onda, la duración del pulso y el fluencia, existe la posibilidad de que el calor generado durante el procedi- miento se difunda a estructuras vecinas epidérmicas que tienen melanina (un cromóforo de amplio espectro), con el riesgo de producir cambios en la pigmentación. Por ello, para proteger la epidermis y la dermis superficial de los efectos fototérmicos no deseados, y para reducir las costras, la discromía y el dolor, se usa el enfriamiento de la piel por medio de gases, líquidos o sólidos. En la refrigeración con gas, el refrigerante es un líquido que se evapora, con una temperatura menor a la de la superficie cutánea, el espray de criógeno se dirige a la superficie de la piel en el mismo sitio de tratamiento. En la refrigeración por contacto con cuerpos sólidos, estos deben tener gran capacidad térmica y conductividad.

Se puede generar la refrigeración de tres formas: refrigeración previa usada para procedimientos con pulsos menores de $5 \mathrm{~ms}$, como el $Q$ switched, en los que se usan pulverizadores de nitrógeno líquido; refrigeración simultánea, útil para pulsos mayores de $5-10 \mathrm{~ms}$ y, finalmente, la refrigeración después del tratamiento, que no es muy aconsejada ${ }^{6}$.

\section{Forma de refrigeración pasiva:}

- Gel acuoso refrigerado.

\section{Formas de refrigeración activa:}

- Refrigeración por conducción: cristal frío, zafiro.

- Refrigeración por evaporación; espray refrigerante.

- Refrigeración por aíre frío. 


\begin{tabular}{|c|c|c|}
\hline Tipo de láser & Longitud de onda & Aplicación cutánea \\
\hline Argón (CW) & $418 / 514 \mathrm{~nm}$ & Lesiones vasculares. \\
\hline $\begin{array}{l}\text { APTD (Argon Pumped Aunable Dye) (casi } \\
\text { continuo) }\end{array}$ & $577 / 585 \mathrm{~nm}$ & Lesiones vasculares. \\
\hline Fosfato potásico de titanio $\left(\mathrm{KTiOPO}_{4}\right)$ & $532 \mathrm{~nm}$ & Lesiones vasculares, lesiones pigmentadas. \\
\hline Vapor de cobre (CW) & $510 / 578 \mathrm{~nm}$ & Lesiones vasculares, lesiones pigmentadas. \\
\hline Nd:YAG & $532 \mathrm{~nm}$ & Lesiones pigmentadas, tatuajes amarillo, rojo o naranja. \\
\hline Luz pulsada & $\begin{array}{l}510 \mathrm{~nm} \\
585-595 \mathrm{~nm}\end{array}$ & $\begin{array}{l}\text { Lesiones pigmentadas. } \\
\text { Lesiones vasculares, cicatrices hipertróficas, queloides, } \\
\text { estrías, verrugas, rejuvenecimiento no ablativo. }\end{array}$ \\
\hline $\begin{array}{l}\text { Rubí } \\
\text { QS } \\
\text { Modo normal }\end{array}$ & $694 \mathrm{~nm}$ & $\begin{array}{l}\text { Lesiones pigmentadas, tatuaje azul, negro o verde. } \\
\text { Remoción de pelo. }\end{array}$ \\
\hline $\begin{array}{l}\text { Alejandrita } \\
\text { QS } \\
\text { Modo normal }\end{array}$ & $755 \mathrm{~nm}$ & $\begin{array}{l}\text { Lesiones pigmentadas, tatuaje azul, negro o verde. } \\
\text { Remoción de pelo, venas en piernas. }\end{array}$ \\
\hline Diodo & $800-810 \mathrm{~nm}$ & Remoción de pelo, venas en piernas. \\
\hline $\begin{array}{l}\text { Nd:YAG } \\
\text { QS } \\
\text { Modo normal }\end{array}$ & $1.064 \mathrm{~nm}$ & $\begin{array}{l}\text { Lesiones pigmentadas, tatuaje azul, negro o verde. } \\
\text { Remoción de pelo, venas en piernas, rejuvenecimiento } \\
\text { no ablativo. }\end{array}$ \\
\hline Erbio:YAG pulsado & $2.490 \mathrm{~nm}$ & Rejuvenecimiento ablativo, lesiones epidérmicas \\
\hline $\begin{array}{l}\text { Dióxido de carbono } \\
\text { CW } \\
\text { Pulsado }\end{array}$ & $10.600 \mathrm{~nm}$ & $\begin{array}{l}\text { Queilitis actínica, verrugas, rinofima. } \\
\text { Rejuvenecimiento ablativo, lesiones epidérmicas, dér- } \\
\text { micas. }\end{array}$ \\
\hline Luz intensa pulsada & 515 a $1.200 \mathrm{~nm}$ & $\begin{array}{l}\text { Lesiones pigmentadas superficiales, lesiones vasculares, } \\
\text { remoción de pelo, rejuvenecimiento dérmico no ablativo. }\end{array}$ \\
\hline Vidrio de erbio & $1.540 \mathrm{~nm}$ & Rejuvenecimiento dérmico no ablativo. \\
\hline Nd:YAG, pulso largo & $1.320 \mathrm{~nm}$ & Rejuvenecimiento dérmico no ablativo. \\
\hline $\begin{array}{l}\text { Diode, PULSO LARGO } \\
\text { CW: onda continua }\end{array}$ & $1.450 \mathrm{~nm}$ & Rejuvenecimiento dérmico no ablativo, acné. \\
\hline
\end{tabular}

TABLA 2. Tipos de láser y aplicaciones cutáneas.

\section{Usos del láser en dermatología}

\section{Lesiones vasculares}

Para los vasos superficiales pequeños, ubicados principalmente en cara y cuello, el cromóforo diana lo constituye la oxihemoglobina que tiene dos picos máximos de absorción, $540 \mathrm{~nm}$ (pico alfa) y $580 \mathrm{~nm}$ (pico beta)7. Por lo tanto, teóricamente son útiles el láser de argón (488$514 \mathrm{~nm})$ y el de vapor de cobre $(578 \mathrm{~nm})$. Sin embargo, estas longitudes de onda tienen limitaciones en la penetración y son absorbidos concomitantemente por la melanina; por ello, han sido reemplazadas por fuentes más predecibles y más seguras, como KTP ( $532 \mathrm{~nm})$, PDL $(585 / 595 \mathrm{~nm})$, alejandrita $(755 \mathrm{~nm})$ y Nd:YAG $(532 \mathrm{~nm})^{8}$.

Los vasos localizados más profundamente, como 

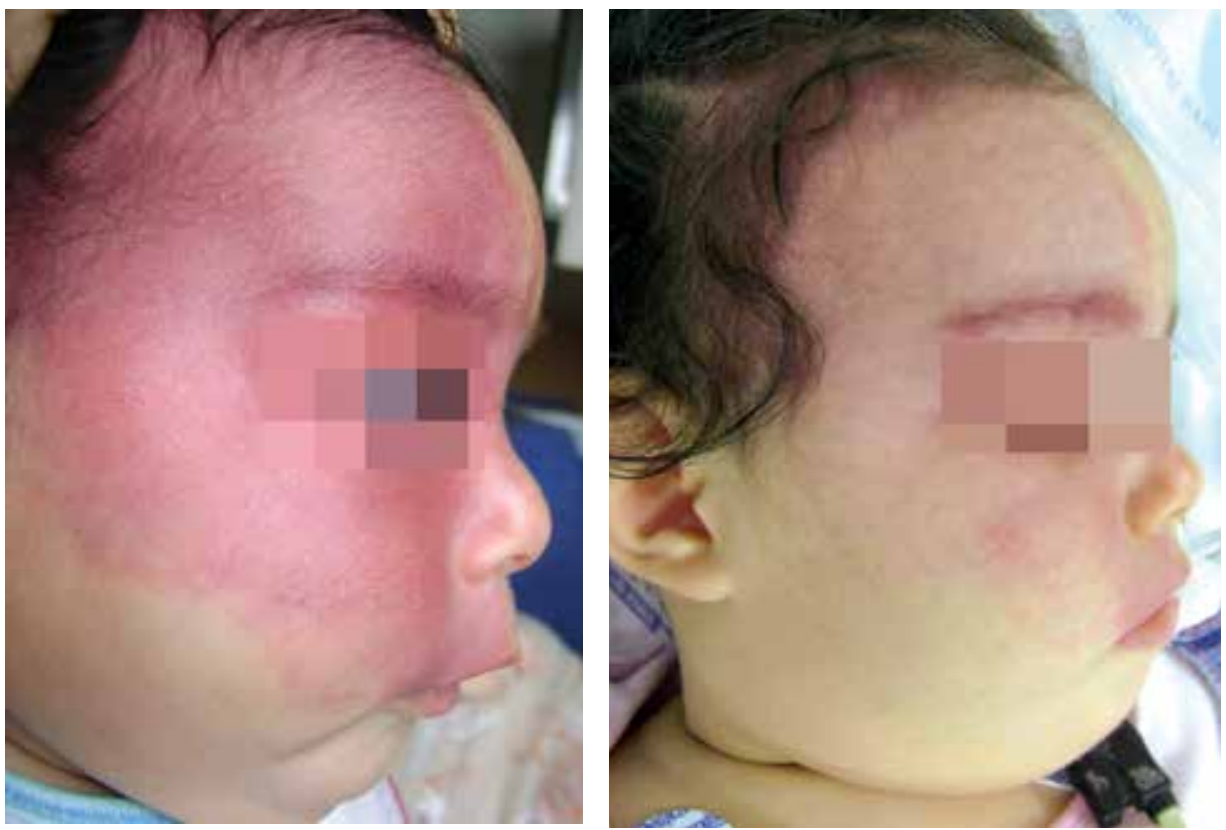

\section{FIGURAS 4 Y 5:}

Malformación vascular capilar: A la izquierda, mancha en vino de oporto; a la derecha, después de cuatro sesiones de tratamiento con láser vascular PDL. aquellos que se encuentran en las piernas, tienen un mayor porcentaje de desoxihemoglobina, que cuenta con un mayor pico de absorción, entre los 800 y 1.200 $\mathrm{nm}$, por lo que longitudes de onda más largas, como la del Nd:YAG (1.064 nm), serían más apropiadas.

Por lo anterior, el sistema que se elija depende de la profundidad y el tipo de la lesión, la historia clínica del paciente, y el tamaño de los vasos: las lesiones rosadas y rojas tienen vasos más pequeños y superficiales, y las púrpuras y azules tienen vasos de mayor tamaño con mayor profundidad.

ARGón: emite un pulso continuo azul-verde con longitudes de onda de 488 a $514 \mathrm{~nm}$; produce un daño térmico no específico, con intervalos de exposición mayores al tiempo de relajación térmica de los vasos, con un alto riesgo de hipopigmentación y cicatrización que hace que actualmente esté en desuso'.

SISTEMAS CASI CONTINUOS: el vapor de cobre, kriptón y KTP producen disparos con pulsos de $20 \mathrm{~ns}$, con intervalos muy cortos que no permiten al vaso un enfriamiento adecuado, lo cual resulta en un daño tisular similar al que se ve con la forma continua, con gran probabilidad de cicatrices hipertróficas y cambios en la textura que han hecho que no sean muy usados.

PDL (PULSED DYE LASER): es el láser de elección para malformaciones vasculares y hemangiomas, pero, además, se usa para rosácea, poiquilodermia, cica- trices hipertróficas y verrugas. Emite una longitud de onda de 585 a $595 \mathrm{~nm}$ que penetra o,65 nm. El efecto secundario más común es la púrpura durante el tratamiento y en los 2 a 14 días posteriores; también se han reportados efectos secundarios, como costras (25\%), sangrado (12\%), hiperpigmentación a largo plazo (27 $\%)$, cicatriz atrófica (3\%), hipopigmentación (1\%) y cicatriz hipertrófica (1\%).

Se utiliza en el tratamiento de las manchas de vino de oporto, requiriéndose varias sesiones, separadas por intervalos de un mes como mínimo. El éxito del tratamiento depende la profundidad y el diámetro de la lesión, así como la localización anatómica; la mejoría de las lesiones en la frente, la parte lateral de la cara, el cuello y el tronco, es mayor y más rápida que la de las localizadas en el centro de la cara o en las extremidades; también, se ha reportado que las lesiones tempranas mejoran más que las de mayor tiempo de evolución ${ }^{10}$. Algunas lesiones profundas son resistentes al tratamiento y requieren de la combinación con lásers de mayor penetración, como el de alejandrita $(755 \mathrm{~nm})$ o el Nd:YAG (1.064nm) ${ }^{11,12}$ (FIGURAS 4 Y 5).

En rosácea y telangiectasias en cara, su uso produce 70 a $100 \%$ de mejoría. La mejoría es buena en los nevus en araña, pero se le debe advertir al paciente la posibilidad de recurrencia que va hasta el $10 \%$ en seis meses.

También, ha sido útil para el tratamiento de telangiectasias y hemangiomas, como se explica más adelante. 

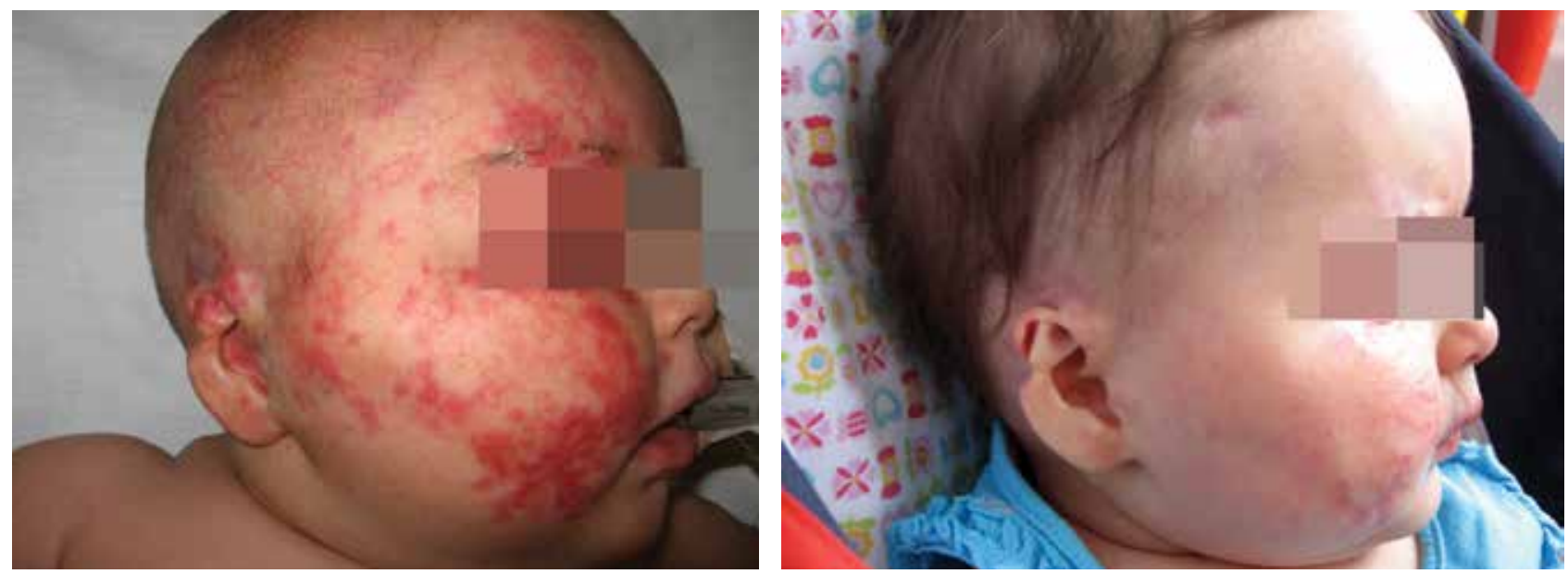

FIGURAS 6 Y 7. Angioqueratomas tratados con una sesión de láser vascular PDL.

\section{Telangiectasias}

Son dilataciones de o,1 a $1 \mathrm{~mm}$ de capilares, vénulas o arteriolas con apariencia clínica eritematosa a violácea. El color de la lesión se relaciona con la saturación de oxígeno, la cual es mayor en las rojas que en las azules; esto determina la fluencia que se debe utilizar. La energía absorbida se convierte en calor, con aumento de la temperatura especialmente en el colágeno de la luz o, en los vasos muy pequeños, en el colágeno perivascular. Posteriormente se genera un espasmo, asociado a coagulación y trombosis, que contribuye también a la desaparición de los vasos. Todo este daño térmico genera un fenómeno inflamatorio con reemplazo del vaso por tejido fibroso. La proporción entre espasmo y trombosis es importante, ya que si se excede en la segunda pueden aparecer efectos adversos. Los pulsos cortos favorecen la ruptura de la pared del vaso, mientras que los largos producen mayor contracción ${ }^{13}$.

Actualmente, hay varios tipos de láser disponibles para el tratamiento de telangiectasias en piernas y deben usarse en vasos de 0,2 a $2 \mathrm{~mm}$; entre ellos están los siguientes.

PDL: cuando los vasos están en la cara, la mejoría es de 70 a $100 \%$. La mejoría de los nevus en araña es buena, pero pueden tener una recurrencia de $10 \%$ en seis meses. Para las telangiectasias en piernas se ha usado láser con pulsos largos.

NEODIMIO:ITRIO-ALUMINIO-GRANATE (ND:YAG 532 NM): tiene longitudes de onda verdes cercanas al pico de la oxihemoglobina. El calor se genera de forma menos uniforme, por lo que no es tan usado para las lesiones vasculares ya que tiene menos efectividad y mayor riesgo de cicatrización.

ND:YAG 1.064 NM: es el láser de elección para telangiectasias, con porcentajes muy altos de mejoría. Requiere fluencias en el rango entre $70 \mathrm{y} 150 \mathrm{~J} / \mathrm{cm}^{2}$, en promedio. Entre los efectos adversos reportados están: dolor, lesiones transitorias de urticaria después del tratamiento y lesiones purpúricas. Debe tenerse cuidado en las lesiones periorbitarias, ya que tiene una alta penetración, hasta de $0,75 \mathrm{~mm}^{14,15,16}$.

En las telangiectasias de las piernas hay mayor riesgo de recidiva por la alteración en el sistema de los vasos comunicantes, por lo que se recomienda practicar estudios vasculares de imaginología y el uso de medias de gradiente, si no están contraindicadas. Los efectos adversos reportados son: púrpura, hiperpigmentación y dolor con el tratamiento ${ }^{17,18}$.

Otras lesiones vasculares que han recibido tratamiento láser con muy buenos resultados son: la poiquilodermia de Civatte, los lagos venosos, las telangiectasias en araña, los angiofibromas, los angioqueratomas, los granulomas telangiectásicos, la rosácea, el eritema facial, la radiodermatitis y la telangiectasia hemorrágica hereditaria (FIGURAS 6 Y 7).

\section{Hemangiomas}

Los hemangiomas son los tumores vasculares más comunes de la infancia. Constituyen crecimientos endoteliales benignos y están presentes en 2 a $3 \%$ de los recién nacidos, en forma de máculas, con una fase proliferativa seguida por una estacionaria y, finalmente, la involución. 

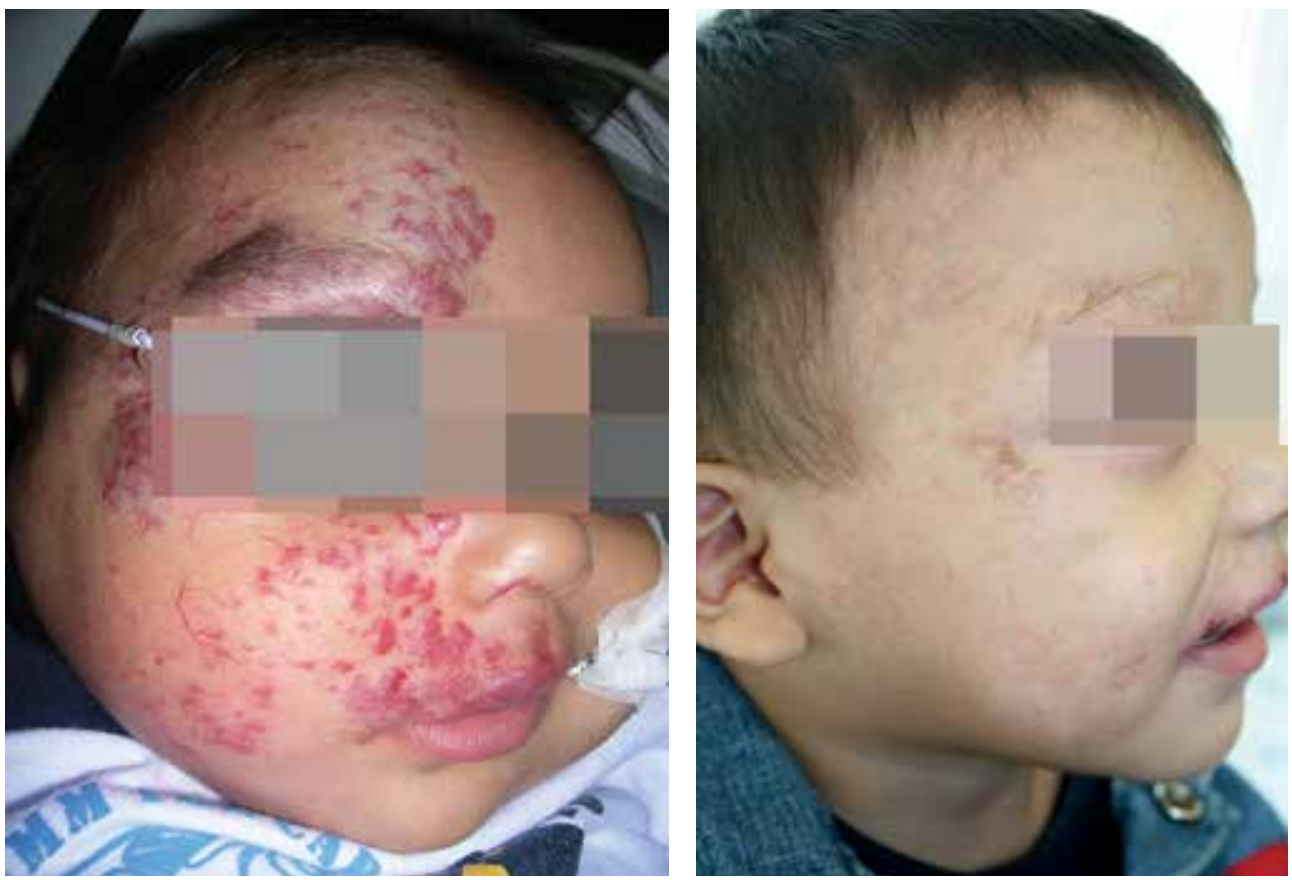

FIGURAS 8 Y 9.

Hemangioma en cara tratado con láser vascular PDL y YAG 1.064 después de cinco sesiones.

Estos tumores vasculares, o hemangiomas, deben tratarse en las siguientes circunstancias:

- Si producen anormalidades funcionales o morfológicas, con compromiso de estructuras vitales, como los ojos o la vía aérea.

- Si están ulcerados o con sangrado.

- Si presentan sobreinfección.

- Si pueden producir desfiguración o cicatrices.

- Si presentan crecimiento, con el objetivo de prevenir futuras anormalidades funcionales o cosméticas.

PDL: en hemangiomas no complicados no hay diferencias en el resultado final entre los tratados y los no tratados con PDL; sin embargo, en algunos estudios se reporta que previenen el crecimiento y aceleran la regresión por estimulación de la apoptosis.

El láser ha demostrado ser efectivo para tratar hemangiomas ulcerados, con disminución del sangrado y de infección, e inducción de nueva epitelialización de las úlceras. Para los hemangiomas profundos se recomienda combinarlo con el Nd:YAG con longitud de onda de $1.064 \mathrm{~nm}$, para aumentar la penetración (FIGURAS 8 Y 9).

\section{Depilación}

Se usa con fines cosméticos y para enfermedades como el acné queloide de la nuca, la foliculitis decalvans y la seudofoliculitis de la barba ${ }^{19,20}$. En la remoción del pelo, el cromóforo buscado es la melanina del tallo piloso, de la vaina radicular externa y de la matriz del folículo piloso, la cual se alcanza con longitudes de onda de 600 a $1.100 \mathrm{~nm}$ que sean selectivas por su penetración dérmica. Sin embargo, la melanina epidérmica puede competir en la absorción y causar alteraciones de la pigmentación; por esta razón, debe usarse tiempos de relajación térmica menores o iguales a los del folículo piloso (10-100 ms, según el diámetro) y, además, debe tenerse en cuenta que el disparo puede producir calentamiento perifolicular. Hay tres medios por los que el láser destruye los folículos pilosos: por daño fototérmico por el calor, que es el principal mecanismo de acción; por daño fotomecánico con daño por la generación de ondas de choque, y por daño fotoquímico por la generación de mediadores tóxicos como los radicales libres de oxígeno.

Los folículos en fase anágena están en la dermis superficial con una división activa, lo que los hace más vulnerables. Para aumentar la tasa de mejoría se recomienda que el paciente se depile con cera ocho semanas antes del procedimiento, para aumentar el porcentaje de folículos en fase anágena. Las áreas con vellos delgados deben tratarse con mucho cuidado, porque se ha reportado que dosis subletales inducen el crecimiento de pelos terminales.

La depilación con láser es menos efectiva en los pelos que no son muy oscuros, por lo que la Food and Drug 
Tipo de láser

Rubí

Alejandrita

Diodo

Nd:YAG

Luz pulsada intensificada

(Intensed Pulsed Light, IPL)

\section{Efecto secundario observado}

Dolor, ampolla, costra, erosión, púrpura, hiperpigmentación o hipopigmentación (cambios pigmentarios y cicatriz en fototipos altos).

Dolor, ampolla, púrpura, hiperpigmentación o hipopigmentación, hipertricosis.

Dolor moderado a intenso, ampolla, costra, erosión, hiperpigmentación o hipopigmentación, hipertricosis.

Púrpura, foliculitis, dolor, hiperpigmentación o hipopigmentación (muy raros, es seguro para fototipos oscuros).

Dolor moderado, eritema, hiperpigmentación o hipopigmentación, crecimiento paradójico de pelo en áreas cercanas a las tratadas.

TABLA 3. Efectos secundarios más comunes con depilación láser según el equipo.

Administration (FDA) aprobó la aplicación de melanina liposómica cuatro días antes del procedimiento en pelos sin pigmentos; además, se está estudiando el uso de azul de metileno como cromóforo.

\section{PREPARACIÓN PARA LA DEPILACIÓN}

La absorción por la melanina del folículo piloso es un factor muy importante en la remoción del pelo, por lo cual los pacientes no deben aplicarse cera durante el tratamiento ni electrólisis antes de la depilación con láser; se permite afeitarse con cuchillas y aplicar cremas depilatorias, ya que el folículo no se altera. Se debe hacer énfasis en los cuidados de exposición al sol antes y después del tratamiento. Debe tenerse especial cuidado con las gafas protectoras durante el procedimiento, en la sala del tratamiento, ya que la retina contiene grandes concentraciones de melanina que se pueden dañar con el láser. Después del tratamiento aparecen lesiones transitorias eritematosas de urticaria y se pueden usar esteroides suaves para disminuir este efecto ${ }^{21}$.

\section{LÁSER PARA DEPILACIÓN}

Actualmente hay varios tipos de láser disponibles para la depilación, aprobados por la FDA: rubí (694 nm), alejandrita $(755 \mathrm{~nm})$, diodo (819 nm), Nd:YAG $(1.064 \mathrm{~nm}) \mathrm{y}$ luz intensa pulsada $(590-1.200 \mathrm{~nm})^{22,23}$.

RUBí: fue el primer láser utilizado para la depilación, es seguro para fototipos bajos, I a III. Algunos estudios muestran $61 \%$ de reducción del pelo con cuatro sesiones de tratamiento en un período de seguimiento de nueve meses. Sin embargo, su comercialización para la depilación actualmente es limitada ${ }^{24}$.

ALEJANDRITA: su eficacia para la depilación a largo plazo varía de 65 a $80,6 \%$. Su uso es seguro en fototipos
I a III. En un estudio no se encontró diferencia significativa en la media de reducción de pelo, entre un grupo de pacientes tratados inicialmente con diodo y posteriormente con alejandrita, en comparación con un grupo similar tratado solo con alejandrita; ambos grupos de pacientes pertenecían a fototipos I a IV. Se reportaron reducciones de $85 \%$ del pelo con cuatro sesiones ${ }^{25}$.

Diodo: hay reducción de 53 a 84 \% de pelo en seguimientos de 20 meses con cuatro sesiones. Se ha demostrado su eficiencia para depilación en pacientes de fototipos III a V, con pocos y transitorios efectos secundarios; además, se ha reportado que es menos doloroso que el ND-YAG. Recientemente se ha recomendado el empleo de menores fluencias $\left(5\right.$ a $\left.15 \mathrm{~J} / \mathrm{cm}^{2}\right)$, con resultados similares en la reducción del pelo, menos molestias y efectos secundarios, en comparación con el uso de fluencias mayores, aun durante el tratamiento de pacientes con fototipo $\mathrm{V}$.

ND:YAG 1064: se considera la mejor opción en depilación láser en fototipos de piel altos, IV a VI, ya que la absorción de la melanina es menor. En pacientes de piel oscura se ha demostrado tolerancia a altas fluencias con pocos eventos secundarios; la utilización de mayores fluencias es controversial, con resultados contradictorios en los diferentes estudios. Se obtiene 50 a $75 \%$ de reducción de pelo con cuatro sesiones en seguimientos de un año.

LUZ INTENSA PULSADA: se trata de una luz policromática, no coherente, entre los 400 y los $1.200 \mathrm{~nm}$, aunque se pueden usar varios filtros para seleccionar un determinado cromóforo. Estos dispositivos transmiten diferentes longitudes de onda y fluencias entre cada pulso, lo que genera resultados variables. No se ha evidenciado con certeza una reducción de pelo a largo plazo con este 
método. En dos estudios se comprobaron resultados inferiores con luz pulsada intensificada (Intensed Pulsed Light, IPL) comparados con los obtenidos con alejandrita y ND-YAG.

DISPOSITIVOS PARA USO EN CASA: utilizan tecnología de luz pulsada intensificada y láser pero con fluencias menores que los aparatos maniobrados por especialistas. La FDA ha aprobado el láser de diodo tria (810 $\mathrm{nm})$ y el IPL Silk'n ${ }^{\circledR}(475$ a $1.200 \mathrm{~nm})$, siendo indispensable el uso de protección ocular. La mayoría de estos aparatos cuentan con un sensor que evita que el rayo de luz se emita si no está en contacto con la piel, de modo que mejore el perfil de seguridad. Su empleo inadecuado o en manos inexpertas, podría causar quemaduras térmicas y daño ocular importante. En un estudio de Wheeland sobre la utilización de un láser de diodo portátil (SpectraGenics, Inc., Pleasanton, CA), se compararon 77 consumidores apropiados (pacientes con fototipos de piel I a IV o con pelo color café claro a negro) contra consumidores inapropiados (cabello gris, rojo, rubio o blanco o con fototipos V y VI). El primer grupo se sometió a tres sesiones de depilación autoadministradas con intervalos de tres semanas. Se encontró una media de de 69,8,\% reducción de pelo, tres semanas después de dos tratamientos, y de 32,7 \%, doce meses después de tres tratamientos. El segundo grupo recibió un único pulso de láser a la máxima fluencia del dispositivo, demostrándose finalmente mayor ocurrencia de efectos adversos en estos pacientes, con ampollas en el $8 \%{ }^{26}$. En el estudio de Mulholland se trataron 34 pacientes utilizando equipo portátil de luz pulsada intensificada (Silk'n $^{\text {TM }}$; Homeskinovations, Kfar, Saba, Israel) y se encontró $74 \%$ de reducción de pelo dos semanas después del primer tratamiento y, $64 \%$, tres meses después del tercer tratamiento ${ }^{27}$.

\section{EFECTOS NO DESEADOS CON DEPILACIÓN} LÁSER

Se han reportado efectos a corto plazo: dolor, edema perifolicular en las primeras 48 horas, ampolla, costra perifolicular, púrpura y urticaria al frío.

Los efectos transitorios (duración de semanas a meses) son hiperpigmentación o hipopigmentación.

Los efectos persistentes son hiperpigmentación, hipopigmentación, cicatriz y atrofia.

Los cambios pigmentarios ocurren con mayor frecuencia en fototipos mayores de IV, en los cuales el $\mathrm{Nd}: Y A G$ ha demostrado ser seguro ${ }^{28}$.

En algunos reportes se habla de hipertricosis paradójica después del tratamiento en $0,6 \%$ de los pacientes, en fototipos IV, probablemente por el uso de fluencias subóptimas ${ }^{29}$.

A continuación se anotan los efectos secundarios más comunes para los diferentes láseres usados en depilación ${ }^{30}$

\section{Fotoenvejecimiento}

RejuVEneCimiento No ABLATivo: se produce por la acción del calor controlado en la dermis, sin daño epidérmico, con formación de nuevo colágeno que reemplaza el dañado por la luz solar. Se ha clasificado de forma arbitraria en tipo 1, con mejoría de cambios pigmentarios, pilosebáceos y vasos, y en tipo 2, con reducción de arrugas ligeras a moderadas o componentes dérmicos. En la primera se buscan la melanina y hemoglobina como cromóforos y en la segunda se usa, además, el agua. Busca longitudes de onda en el rango del infrarrojo (1.000 a $1.500 \mathrm{~nm}$ ) con poca absorción en tejidos superficiales que contienen agua y penetración a tejidos profundos.

PDL: es absorbido por los vasos dérmicos, con liberación de mediadores inflamatorios que aumentan la actividad fibroblástica y la producción de colágeno. Se usan piezas de mano de 507 .

ND:YAG: forma colágeno en la dermis papilar con mejoría de las arrugas y algunas cicatrices atróficas.

También se ha usado el diodo.

Rejunenecimiento ablativo: Se hace con láser $\mathrm{CO}_{2} \mathrm{y}$ erbio:YAG. Sus indicaciones son fotoenvejecimiento, discromías, cicatrices atróficas y arrugas. El efecto buscado es una remoción de la epidermis con un daño térmico residual dérmico. Con el $\mathrm{CO}_{2}$ se hace por medio de la producción de calor con desnaturalización de colágeno de tipo I, que produce formación de nuevo colágeno y un acortamiento de las fibras, aproximadamente, del $30 \%$. Entre los efectos secundarios están el edema, las costras y la sensación de quemadura. Esta última es, en general, mayor que la producida por el Er:YAG; para evitarla en áreas pequeñas se usa anestesia local, pero en zonas extensas debe usarse sedación o anestesia general. Los resultados son una mejoría del $50 \%$ en la tonicidad de la piel, la profundidad de las cicatrices y las arrugas ${ }^{31}$.

El Er:YAG tiene gran afinidad por el agua y la ablación se alcanza con menos daño térmico residual. Trabaja en la epidermis, que está compuesta en un $90 \%$ por agua, con una ablación de 2 a $5 \mu \mathrm{m}$ de profundidad y en algunos sitios con necrosis térmica hasta de $10 \mu \mathrm{m}$. Los estudios histológicos inmediatamente después del tratamiento muestran necrosis por coagulación con una 
extensión hacia la epidermis proporcional a la fluencia del láser; al día 7 la epidermis está totalmente regenerada, con proliferación de queratinocitos y remanentes de colágeno dañado, y al día 21 hay regeneración subepidérmica con tejido basófilo edematoso. Se aplica el principio de daño térmico selectivo con pulsos de menos de 1 ms de duración ${ }^{31}$.

Contraindicaciones absolutas para el rejuvenecimiento con láser:

- Expectativas irreales

- Tratamiento con isotretinoína en los últimos doce meses

Contraindicaciones relativas para el rejuvenecimiento con láser:

- Historia personal o familiar de vitiligo o esclerodermia

- Enfermedades que produzcan fenómeno de Koebner

- Tratamiento con radiación

- Tendencia a queloides

- Embarazo o lactancia

\section{Complicaciones}

\section{Complicaciones tempranas:}

Incluyen infección bacteriana, viral o fúngica, que se reduce con la aplicación profiláctica de antibióticos, antivirales o antifúngicos y esquemas de higiene de la herida.

El acné se puede presentar uno a dos meses después del tratamiento, por el uso de emolientes.

La dermatitis de contacto puede presentarse uno a cuatro meses después del tratamiento; debe evitarse el uso de champú y productos con perfume durante la primera semana.

\section{Complicaciones tardías:}

Hiperpigmentación posinflamatoria: dos semanas a seis meses después del tratamiento, es la complicación más común, generalmente en fototipos IV, V y VI.

Hipopigmentación relativa: se produce un mes después del tratamiento por remoción de la piel crónicamente bronceada que vuelve a su color natural.

Hipopigmentación sostenida: es causada 5 a 12 meses después del tratamiento, posiblemente por pérdida de melanocitos, y puede acompañarse de cambios en la textura por cicatriz fibrosa.

Eritema prolongado: se presenta a los tres o más meses después del tratamiento, por liberación de citocinas en el proceso de cicatrización y vasodilatación; es mayor con el $\mathrm{CO}_{2}$, su duración es proporcional a la profundidad del daño térmico y puede mejorarse con esteroides tópicos.

Cicatrización: es una complicación rara cuando se usan las técnicas adecuadas ${ }^{33}$.

\section{Fototermólisis fraccionada}

Produce heridas microscópicas por calor, llamadas 'zonas de tratamiento microtérmico', con zonas necróticas de 100 a $160 \mu \mathrm{m}$, aproximadamente, rodeadas por zonas de tejido viable, en patrones geométricos que no dependen de la distribución del cromóforo; las zonas de tratamiento microtérmico corresponden a 15 a $25 \%$ de toda el área tratada en cada sesión ${ }^{34}$. Los parámetros del láser se ajustan, produciendo varias profundidades y diferentes distancias en micras entre los puntos; la recuperación es más rápida, porque hay tejido sano que estimula una nueva epitelialización entre los puntos de disparo. Es bien tolerada, con rápida reparación dermoepidérmica ${ }^{35,36}$.

Las arrugas faciales y periorbitarias leves a moderadas, así como el fotodaño, son algunas de las principales indicaciones del láser fraccionado ya sea ablativo o no ablativo, aunque se han reportado mejores resultados y mayor índice de satisfacción de los pacientes con la técnica ablativa. En varios estudios en que se compara los tratamientos fraccionados con $\mathrm{CO}_{2}$ y con erbio, se ha encontrado mayor índice de mejoría con el primero. En las cicatrices de acné superficiales y de profundidad media se han obtenido buenos resultados con esta modalidad de tratamiento, aunque las profundas y en picahielo muestran menos mejoría ${ }^{37}$.

El láser fraccionado también se ha utilizado en cicatrices secundarias a quemaduras y cirugías, estrías, melasma, pigmentación posinflamatoria, poiquilodermia de Civatte, nevus de Ota y granuloma anular, entre otros; sin embargo, con respecto a estas indicaciones solo existen pocos reportes, los resultados son controversiales y no se recomienda su uso rutinario ${ }^{38}$.

\section{Cicatrices y queloides}

Las cicatrices son de varios tipos. Las hipertróficas muestran proliferación anormal de colágeno limitada al área de daño epitelial durante la fase de remodelación de la herida, pueden ser rojas, nodulares con evolución a queloide o involución. Los queloides, por el contrario, son cicatrices que traspasan los límites del daño cutáneo inicial. Además, las cicatrices pueden ser atróficas o pigmentadas. 

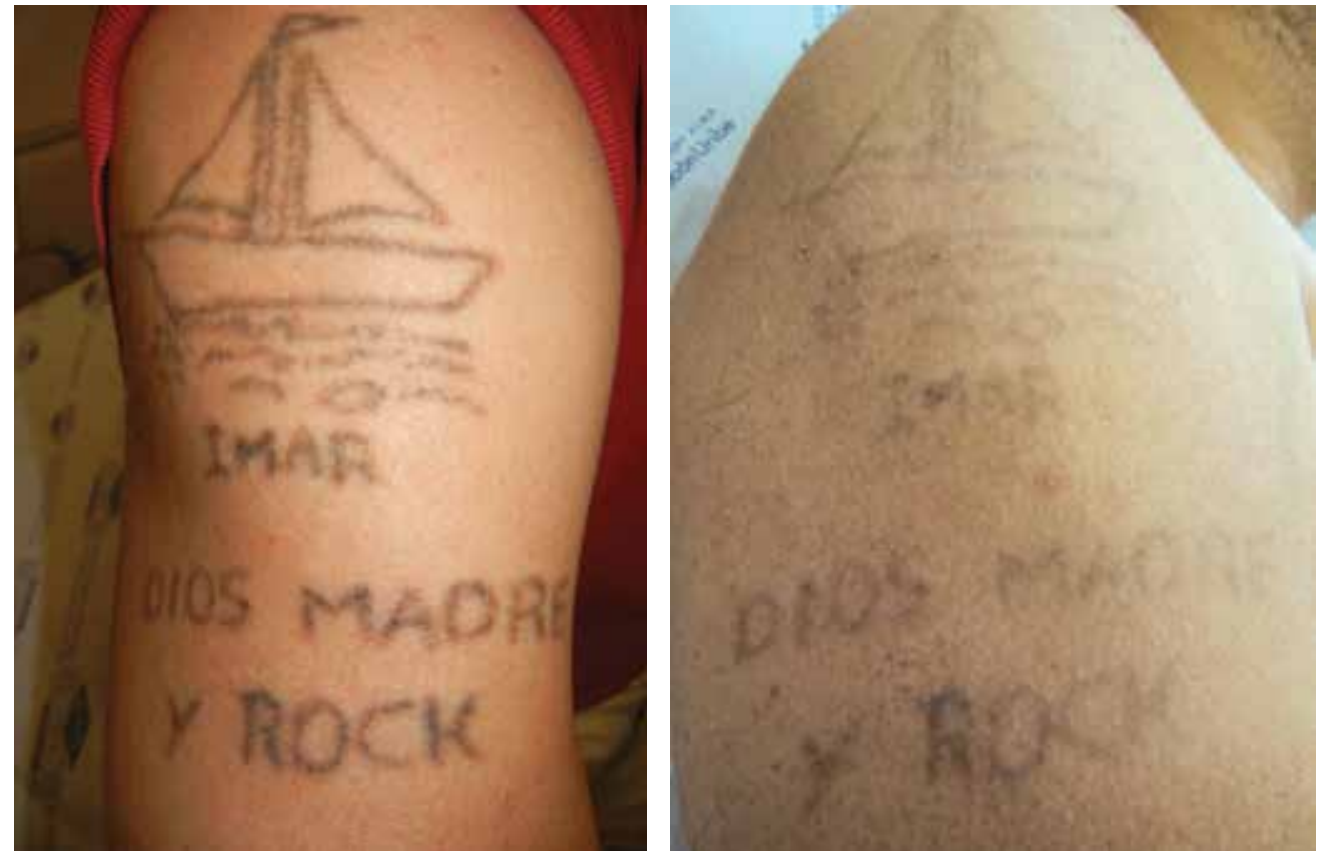

FiguRAS 10 Y 11.

Tatuaje negro tratado con láser YAG 1064 Q Switch.
El argón y el $\mathrm{CO}_{2}$ fueron usados inicialmente, pero presentaron altas tasas de recidivas o empeoramiento de las cicatrices por el daño tisular no selectivo.

El láser PDL se considera actualmente un tratamiento de primera línea en cicatrices hipertróficas y queloides. Su mecanismo de acción no es claro; se cree que induce hipoxia tisular, que lleva a catabolismo y disminución de la función celular, con alteración de los puentes disulfuro de colágeno que lleva a reordenamiento de sus fibras ${ }^{39}$.

Las tasas de mejoría reportadas están entre 57 y $83 \%$, con fluencias de 5 a $7 \mathrm{~J} / \mathrm{cm}^{2}$ e intervalos entre sesiones de seis a ocho semanas. La mejoría es mayor en las cicatrices hipertróficas que en los queloides.

Las cicatrices atróficas han sido tratadas con buenos resultados con el erbio:YAG ${ }^{40}$.

\section{Lesiones pigmentadas}

\section{Tatuajes}

Los tatuajes se comportan como cromóforos exógenos; el cromóforo buscado es la tinta que se encuentra en la dermis. Cuando la tinta se implanta, es fagocitada por fibroblastos dérmicos y permanece indefinidamente en la dermis reticular y papilar. Los realizados por personas no expertas son menos densos y de profundidad variable, y contienen tinturas con bases de carbón; los hechos por profesionales tienen pigmentos de colores, con profundidad uniforme. En general, los láseres de pulsos cortos $Q$ switch con longitudes de onda de 532 a $1.064 \mathrm{~nm}$, son los ideales porque poseen un efecto fotoacústico con el cual se generan ondas que chocan con las células con pigmento y las rompen; posteriormente, hay fagocitosis y eliminación linfática. Su destrucción se produce por la fragmentación de las partículas de tatuaje y la muerte selectiva de las células que contienen el pigmento, con remoción por eliminación transepidérmica y por macrófagos dérmicos.

En general, se acepta que los tatuajes 'acrales', realizados por profesionales y de mucho tiempo, son más difíciles de eliminar ${ }^{41}$. Además, debe tenerse en cuenta que las tintas rojas y amarillas tienen dióxido de titanio y óxido de hierro, que pueden sufrir oscurecimiento paradójico (FIGURA 10 Y 11).

Los láser usados son los siguientes: (TABLA 4)

RUBí: penetra, aproximadamente, $1 \mathrm{~mm}$; se usa para tatuajes con tinta azul, negra y verde; puede producir hipopigmentación transitoria por daño de los melanocitos. Se necesitan de cuatro a seis tratamientos para tatuajes negros y azules.

ND:YAG 532 NM: tienen el riesgo de mostrar gran afinidad por la melanina que puede producir hipopigmentación; generan púrpura transitoria por la absorción de la hemoglobina. 


\begin{tabular}{ccccc}
\hline Láser & Negro & Azul & Verde & Rojo \\
\hline Alejandrita, $755 \mathrm{~nm}$ & $\mathrm{x}$ & $\mathrm{x}$ & $\mathrm{X}$ & \\
Rubí, 694 $\mathrm{nm}$ & $\mathrm{x}$ & $\mathrm{x}$ & $\mathrm{X}$ & \\
Nd:YAG, $1.064 \mathrm{~nm}$ & $\mathrm{x}$ & $\mathrm{x}$ & & \\
Nd:YAG, $532 \mathrm{~nm}$ & & & & $\mathrm{x}$ \\
\hline
\end{tabular}

TABLA 4. Elección de láser según el color de la tinta.
ND:YAG 1064 NM: su penetración es mayor, lo que disminuye el riesgo de hipopigmentación.

AlejANDRITA 755 NM: es efectivo en tatuajes verdes, negros o azules ${ }^{42}$.

\section{Las Lesiones pigmentadas pueden clasifi- carse en:}

LESIONES EPIDÉRMICAS: lentigo solar, efélides, máculas café con leche, nevus epidérmicos y dermatosis papulosa negra.

LESIONES DÉRMICAS O DERMOEPIDÉRMICAS: neVUS azul, nevus de Ota o Ito, nevus melanocítico, hiperpigmentación por medicamentos, hiperpigmentación infraorbitaria, nevus de Becker y nevus de Spilus.

TATUAJES: mencionados anteriormente. El crómoforo en estas lesiones depende de la naturaleza del pigmento (endógeno o exógeno), la distribución en el tejido (intracelular o extracelular), y la localización anatómica en la piel (epidérmico o dérmico). La melanina tiene un amplio rango de absorción: desde el ultravioleta, pasando por la luz visible, hasta el infrarrojo. Para evitar efectos secundarios es necesario usar longitudes de onda que no sean absorbidos por otros cromóforos y que penetren profundamente en la piel; esto se logra con rangos entre 630 y $1.100 \mathrm{~nm}$. Es importante, además, tener en cuenta la duración del pulso, ya que el blanco buscado es el melanosoma, el cual con cortos pulsos sufre daño de la membrana y desorganización de organelas internas; $\mathrm{su}$ tiempo de relajación térmica va de 250 a 1.000 ns, según el tamaño, y por ello se requieren pulsos de menos de 1 $\mu$ s para su daño selectivo.

Se cree que el daño causado causa expansión térmica que lleva a evaporación local, con generación de ondas acústicas que dañan el núcleo y la célula ${ }^{43}$.

Para lesiones epidérmicas se usan longitudes de onda corta, absorbidas por la melanina superficial: Nd:YAG $Q$ Switch de $532 \mathrm{~nm}$, rubí de $694 \mathrm{~nm}$, alejandrita de $755 \mathrm{~nm}$.

EFELIDES: se usa $Q$ switch con longitudes de onda de 510, 532, 694 y $755 \mathrm{~nm}$.

MANCHAS CAFÉ CON LECHE: hay poca mejoría con el tratamiento, con recurrencias hasta de $67 \%$; se recomienda hacer una prueba previa por el riesgo de oscurecimiento paradójico.

LÉNTIGOS: se utiliza una longitud de onda de $532 \mathrm{~nm}$.

\section{Lesiones dermoepidérmicas}

El tratamiento con láser es poco recomendado para el melasma dermoepidérmico por la escasa mejoría y el riesgo significativo de oscurecimiento después del tratamiento.

NEVUS DE 0TA E ITO: se recomiendan sistemas ultrapulsados, que producen buena respuesta terapéutica con cuatro a ocho sesiones. Se recomiendan: alejandrita $Q$ switch $(755 \mathrm{~nm})$, rubí $Q$ switch $(694 \mathrm{~nm})$ y Nd:YAG $Q$ switch $(1.064 \mathrm{~nm})$. Van dirigidos a células dérmicas, $\mathrm{y}$ se obtiene mejorías de 40 al $90 \%$ con siete sesiones; generalmente, los resultados son definitivos cuando desaparece el nevus. Los efectos adversos reportados son hipopigmentación transitoria, hiperpigmentación y sensación de quemadura ${ }^{44}$ (FIgURAS 12 Y 13).

\section{Láser y acné}

Es un trastorno común y son cuatro los principales factores que contribuyen a su formación: P. acnes, aumento de la producción de sebo, hiperqueratinización folicular e inflamación folicular.

Propionibacterium acnes produce cromóforos endógenos llamados porfirinas, como parte de su proceso metabólico; estas tienen absorción de longitudes de onda entre 400 y $700 \mathrm{~nm}$, con un efecto fototóxico sobre el microorganismo ${ }^{45}$.

Para las cicatrices deprimidas del acné se ha usado la fototermólisis fraccionada, con buenos resultados terapéuticos en pocas sesiones ${ }^{46}$.

\section{Psoriasis y vitíligo}

Se ha usado el láser de excímeros de xenón de $308 \mathrm{~nm}$, que emite longitudes de onda en el espectro ultravioleta; su blanco es el ADN de los linfocitos, que lleva a 

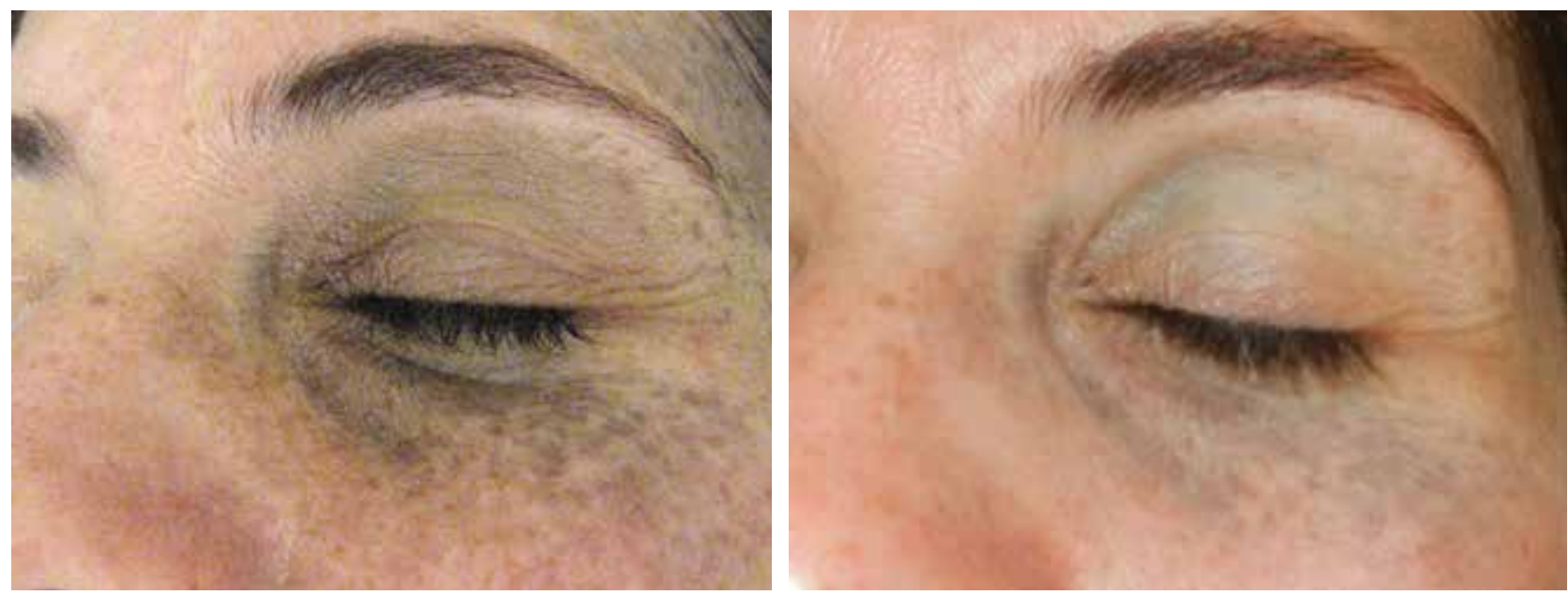

FigURAS 12 Y 13. Nevus de Ota tratado con láser Rubí y YAG 1064 Q Switch.

apoptosis. Se usa cuando el compromiso es de menos de $20 \%$ de la superficie corporal, y se obtiene remisión en 7 a 11 sesiones. En el vitíligo se cree que hay una acción directa sobre los melanocitos ${ }^{47}$.

\section{Tratamiento fotodinámico}

Consiste en la aplicación de ácido aminolevulínico o metilaminolevulínico tópico con oclusión en una capa de $1 \mathrm{~mm}$, aproximadamente, con márgenes de 5 a 10 $\mathrm{mm}$, tres a seis horas antes del procedimiento; después se hace la irradiación, preferiblemente con luces rojas entre 630 y $690 \mathrm{~nm}$. El medicamento actúa por porfirinas activas que sensibilizan la célula a la acción de la luz, después se forman radicales libres de oxígeno que llevan a necrosis selectiva de las células tumorales. Fue aprobado por la FDA para el tratamiento de queratosis actínicas en 1997, pero también se ha usado para queilitis actínica, carcinoma escamocelular, basocelular, micosis fungoides y enfermedad de Bowen, y podría tener un importante potencial en dermatosis inflamatorias, como el acné y la psoriasis. Los efectos secundarios incluyen dolor, hiperpigmentación y aumento de la sensibilidad a la luz ${ }^{48}$.

Szeimies, et al., compararon el ácido metilaminolevulínico y la crioterapia en 202 pacientes con 732 queratosis actínicas. Encontraron resolución completa de $69 \%$ de las lesiones tratadas con fototerapia dinámica frente a $75 \%$ con crioterapia; el resultado cosmético, evaluado por los pacientes y por los investigadores, fue mucho mejor para el primer grupo ${ }^{49}$.

Wang, et al., compararon la criocirugía con la fototerapia dinámica con ácido aminolevulínico, en 44 pa- cientes con carcinoma basocelular superficial. Con la fototerapia dinámica se necesitaron nuevas sesiones en el $30 \%$ de los casos, y con la criocirugía, en el $3 \%$. No se encontraron diferencias estadísticas con respecto a la eficacia y el resultado estético fue mucho mejor en el primer grupo ${ }^{50}$. En 17 pacientes con queratosis actínicas, Kurwa, et al., evaluaron la efectividad de la fototerapia dinámica en comparación con el 5 -fluoruracilo al $5 \%$ aplicado dos veces al día durante tres semanas; no se encontraron diferencias significativas en la efectividad, pero sí en el resultado estético ${ }^{51}$.

En conclusión, se presenta un artículo de revisión del láser en dermatología, una tecnología cada vez más usada en nuestro medio.

\section{Referencias}

1. Acland KM, Barlow RJ. Lasers for the dermatologist. Br J Dermatol. 2000;143:244-55.

2. Liper GM, Rox AR. Lasers in dermatology. In: Freedberg I, Eisen A, editors. Fitzpatrick's Dermatology in General Medicine. 8th edition. Kansas: McGraw-Hill; 2013 p. 249-515. 12941347

3. Tanzi EL, Lupton JR, Alster TS. Lasers in dermatology: Four decades of progress. J Am Acad Dermatol. 2003;49:1-31.

4. Sachdev M, Hameed S, Mysore V. Nonablative lasers and nonlaser systems in dermatology: Current status. J Dermatol Venereol Leprol. 2011;77:380-8.

5. Robinson J, Hanke C, Sengelmann R, Siegel D. Surgery of the skin. Iowa: Elsevier; 2005. p. 575-644.

6. Hamzavi I, Lui H. Using light in dermatology: An update on lasers, ultraviolet phototherapy, and photodynamic therapy. Dermatol Clin. 2005;23:199-207.

7. Adamic M, Troilius A, Adatto M, Drosner M, Dahmane R. Vascular lasers and IPLS: Guidelines for care from the European Society for Laser Dermatology (ESLD). J Cosmet Laser Ther. 2007;9:113-24. 
8. Railan D, Parlette EC, Uebelhoer NS, Rohrer TE. Laser treatment of vascular lesions. Clin Dermatol. 2006;24:8-15.

9. Alster TS, Railan D. Laser treatment of vascular birthmarks. J Craniofac Surg. 2006;17:720-3.

10. Smith JM, Bauland CG, Wijnberg DS, Spauwen PH. Pulsed dye laser treatment, a review of indications and outcome based on published trials. Br J Plast Surg. 2005;58:981-7.

11. Astner S, Anderson RR. Treating vascular lesions. Dermatol Ther. 2005;18:267-81.

12. Kauvar AN, Wang RS. Laser treatment of cutaneous vascular anomalies. Lymphat Res Biol. 2004;2:38-50.

13. Ross EV, Domankevitz Y. Laser treatment of leg veins: Physical mechanisms and theoretical considerations. Lasers Surg Med. 2005;36:105-16.

14. Eremia S, Li CY. Treatment of face veins with a cryogen spray variable pulse width 1,064 nm Nd:YAG laser: A prospective study of 17 patients. Dermatol Surg. 2002;28:244-7.

15. Baumler W, Ulrich H, Hartl A, Lanthaler M, Shafirstein G. Optimal parameters for the treatment of leg veins using Nd:YAG lasers at 1,064 nm. Br J Dermatol. 2006;155:364-71.

16. Goldman MP. Optimal management of facial telangiectasia. Am J Clin Dermatol. 2004;5:423-34.

17. Alster TS, Lupton JR. Lasers in dermatology. An overview of types and indications. Am J Clin Dermatol. 2001;2:291-303.

18. Massey RA, Marreo G, Goen-Bansal M, GmyreK R, Katz BE. Lasers in dermatology: A review. Cutis. 2001;67:477-84.

19. Ross EV, Cooke, LM, Timko AL. Treatment of pseudofolliculitis barbae in skin types IV, V, and VI with a long-pulsed neodymium:yttrium aluminum garnet laser. J Am Acad Dermatol. 2002;47:263-70.

20. Kelly AP. Pseudofolliculitis barbae and acne keloidalis nuchae. Dermatol Clin. 2003;21:645-53.

21. Wanner M. Laser hair removal. Dermatol Ther. 2005;18:209-16.

22. Toosi P, Sadighaa A, Sharifian A. A comparison study of the efficacy and side effects of different light sources in hair removal. Lasers Med Sci. 2006;21:1-4.

23. Haedersdal M, Wulf HC. Evidence-based review of hair removal using lasers and light sources. J Eur Acad Dermatol Venereol. 2006;20:9-20.

24. Obrahimi OA, Avram MM, Hanke CW, Kilmer SL, Anderson RR. Laser hair removal. Dermatol Ther. 2011;24:94-107.

25. Gan SD, Graber EM. Laser hair removal: A review. Dermatol Surg. 2013;17:1-16.

26. Wheeland RG. Simulated consumer use of a battery-powered, hand-held, portable diode laser $(810 \mathrm{~nm})$ for hair removal: A safety, efficacy and ease-of-use study. Lasers Surg Med. 2007;39:476-93.

27. Mulholland RS. Silk'n ${ }^{\mathrm{TM}}$ - A novel device using Home Pulsed Light $^{\mathrm{TM}}$ for hair removal at home. J Cosmet Laser Ther. 2009;11:106-9.

28. Yee S. Laser hair removal in Fitzpatrick type IV to VI patients. Facial Plast Surg. 2005;21:139-44.

29. Alajlan A, Shapiro J, Rivers JK, McDonald N, Wiggin J. Paradoxical hypertrichosis after laser depilation. J Am Acad Dermatol. 2005;53:85-8.
30. Lim SP, Lanigan MW. A review of the adverse effects of laser hair removal. Lasers Med Sci. 2006;21:121-5.

31. Dierickx H, Anderson RR. Visible light treatment of photoaging. Dermatol Ther. 2005;18:191-208.

32. Drnovsek B, Beltram M, Pizem J. Repetitive Er:YAG laser irradiation of human skin: A histological evaluation. Lasers Surg Med. 2004;35:146-51.

33. Railan D, Kilmer S. Ablative treatment of photoaging. Dermatol Ther. 2005;18:227-41.

34. Goel A, Krupashankar DS, Aurangabadkar S, Nischal KC, Omprakash HM, Mysore V. Fractional lasers in dermatology - Current status and recommendations. Indian J Dermatol Venereol Leprol. 2011;77:369-79.

35. Manstein D, Herron GS, Sink RK, Tanner H, Anderson RR. Fractional photothermolysis: A new concept for cutaneous remodeling using microscopic patterns of thermal injury. Lasers Surg Med. 2004;34:426-38.

36. Nelson JS. Dermatologic laser surgery. Lasers Surg Med. 2000;26:105-7.

37. Lamberg L. Future bright for light as dermatologic tool. JAMA. 2002;287:1788-92.

38. Goldman L. Future of laser dermatology. Lasers Surg Med. 1998;22:3-8.

39. Lupton JR, Alster TS. Laser scar revision. Dermatol Clin. 2002;20:55-65.

40. Bradley DT, Park SS. Scar revision via resurfacing. Facial Plast Surg. 2001;17:253-62

41. Mariwalla K, Dover JS. The use of lasers for decorative tattoo removal. Skin Therapy Lett. 2006;11:8-11.

42. Bernstein EF. Laser treatment of tattoos. Clin Dermatol. 2006;24:43-55.

43. Stratigos AJ, Dover JS, Arndt KA. Laser treatment of pigmented lesions--2000: How far have we gone? Arch Dermatol. 2000;136:915-21.

44. Moreno-Arias GA, Camps A. Treatment of nevus of Ota with the Q-switched alexandrite laser. Lasers Surg Med. 2001;28:451-5.

45. Nouri K, Ballar CJ. Laser therapy for acne. Clin Dermatol. 2006;24:26-32.

46. Kazegawua T, Matzucura T, Mizuno Y, Yasushi Suga, Hideoki Ogawa, Shigaku Ikeda. Clinical trial of a laser device called fractional photothermolysis system for acne scars. J Dermatol. 2006;33:623.

47. Passeron T, Orttone JP. Use of the 308-nm excimer laser for psoriasis and vitiligo. Clin Dermatol. 2006;24:33-42.

48. Armenakas A. Laser-mediated photodynamic therapy. Clin Dermatol. 2006;24:16-25.

49. Szeimies RM, Karrer S, Radakovic-Fijan S, Tanew A, CalzavaraPinton PG, Zane C, et al. Photodynamic therapy using topical methyl 5-aminolevulinate compared with cryotherapy for actinic keratosis: A prospective, randomized study. J Am Acad Dermatol. 2002;47:258-62.

50. Wang I, Bendsoe N, Klinteberg CA, Enejder AM, AnderssonEngels S, Svanberg S, et al. Photodynamic therapy Vs. cryosurgery of basal cell carcinomas: Results of a phase III clinical trial. Br J Dermatol. 2001;144: 832-40.

51. Kurwa HA, Yong-Gee SA, Seed PT, Markey AC, Barlow RJ. A randomized paired comparison of photodynamic therapy and topical 5 -fluorouracil in the treatment of actinic keratoses. J Am Acad Dermatol.1999;41:414-8. 